\title{
Racism and dehumanisation in Heart of Darkness and its Italian translations: A reader response analysis
}

\begin{abstract}
This paper presents the results of a reader response study of Joseph Conrad's Heart of Darkness and two of its Italian translations. Specifically, data from an online questionnaire are used to test whether English and Italian readers respond differently to the potential racist implications of the fictional representation of the African natives. Whereas one translator removes completely all occurrences of nigger $(s)$ and negro, the other adds additional uses of the slurs which are not present in the original. We explore with empirical methods whether these translational alterations have an effect on the readers' perception of dehumanisation, discrimination, and racism in the text, comparing responses to each translation with responses to the original. Our findings show evidence of significant differences in the responses between one translation and the original, but also suggest that other linguistic and extra-linguistic factors could be influencing readers' response. With this paper, we aim to make a contribution to the under-researched application of reader response approaches to translation studies.
\end{abstract}

\section{Keywords}

Reader response, translation, racism, dehumanisation, manipulation, Heart of Darkness, Joseph Conrad

\section{Introduction}

It is widely accepted among translation theorists that translating, far from being an act of neutral reproduction, inevitably alters the original and results in differences between the source text (ST) and the target text (TT). As Hermans (2014 [1985]: 11) famously puts it, 'all translation implies a degree of manipulation of the source text for a certain purpose'. According to Lefevere (1992), the purpose is that of making the translation function in a given socio-cultural context in a certain way. Through 'rewriting' (Lefevere 1992) the ST, the translator can shape the TT in order to foster or hinder a given interpretational and/or ideological reading. Farahzad (2003), for example, finds that Persian translators alter syntactic and lexical features of an English text about feminism in order to fit it into their own ideological frameworks. Even though Farahzad (2003: 280) recognises that manipulative shifts can be either deliberate or 
unintentional, he maintains that manipulation is nevertheless ideologically motivated, whereas Dukāte (2009) acknowledges that a distortion of the ST can also result from accidental, hence un-ideological, errors of the translator. Dukāte (2009: 88) explains that a series of mistakes due to carelessness or lack of language and/or world knowledge, for instance - 'can have a cumulative manipulative effect and as a result a text may seem to be factually, linguistically or ideologically manipulated'. Venuti (2013) adds a third category, the 'unconscious', to these causes of manipulation. This category is drawn from psychoanalytic theory, particularly the work of Freud and Lacan, and refers to the differences in translation that are 'symptomatic of an unconscious motivation, a repressed anxiety, an unsatisfied desire' (Venuti, 2013: 55). Although they are connected to the unintentional category discussed by Dukāte (2009), unconscious causes differ in being a product and a reflection of the translator's psyche, rather than a result of mistakes or oversights.

Whether intentionally made or unconscious, ideological or unmotivated, alterations in translation have the potential to trigger a reading of the TT that differs in some respect from that of the ST. Many studies have focused on identifying and examining the stylistic changes that can produce these different reading effects, comparing original and translated texts. It is only through comparison, Munday (2014: 14) explains, that 'any alteration, muffling, exaggeration, blurring, or other distortion of the authorial voice' will come to the fore. Despite the shared use of comparison as analytical technique, the range of linguistic features discussed by these studies, as well as the approaches adopted, vary greatly. Yu (2017), for example, carries out a register study, examining the relationship between dialects and varieties of standard language in a Chinese version of The Adventures of Huckleberry Finn and its original. She explains that different varieties of standard language can be used as sociolects, against with dialects are contrasted. In her study, Yu (2017) finds that the use of standard language as a sociolect has been omitted in the Chinese translation of Huckleberry Finn; this alteration affects the linguistic hierarchy between language varieties in the novel (Yu 2007: 62). Boase-Beier (2014) brings narratology to the study of literary translation, examining narrative structures in the English translation of Herta Müller's novels. Through the discussion of six extract comparisons, she shows that narrative perspectives are changed in translation, altering the sense of focalisation in the TTs and the degree to which the reader has to rely on the text to fill context gaps due to lacking culture-specific background schemata. Morini (2007) uses instead pragmatics and conversation analysis to compare dialogues in Emma and in three Italian translations. He examines whether and how the multitude of implicatures and implicit meanings that characterise Emma's dialogues have been reproduced in the Italian TTs. Corpus 
approaches too have been extensively employed to support the comparative study of translation (see for example Author1, 2017; Author1 \& Colleague, 2017; Johnson, 2016; Čermáková, 2015; Čermáková \& Fárová, 2010; Winters, 2009, 2010; Bosseaux, 2004, 2006), not only because corpus tools can enhance the comparison of texts, but also because they offer a wider range of analytical possibilities unachievable without the help of the computer. The studies here mentioned have confirmed the theorists' claim that textual alterations are intrinsic features of the translated text, showing with concrete evidence that the act of translating creates a new text, as opposed to copying transparently an existing one. However, despite the wealth of research that has showed the linguistic nature of translational alterations, the discussion of the effects that these alterations can have on the target reader's response to the text remains mostly hypothetical.

The empirical study of translation response and reception is an under-researched area. Research on the reading of translations has often been either evaluative, with a focus on translation criticism (Chan, 2016: 121), or mainly theoretical, based on abstract conceptualisations of the reader (Kruger, 2012: 218). However, 'the question of how particular translation strategies affect readers' responses [...] is an empirical one, requiring carefully justified and methodically executed quantitative and qualitative research designs if it is to be answered in a reliable and responsible way' (Kruger, 2012: 218). This paper adopts an empirical approach to study translation response, aiming to redress the existing gap in the field. It carries out a reader response analysis of Joseph Conrad's Heart of Darkness and two of its Italian translations. More specifically, the study reported in this paper uses an online questionnaire to survey readers' reactions to a central interpretational element of Conrad's short novel; that is, the representation of the African natives. By establishing a twofold comparison - ST vs. TTs and TT vs. TT - this study adds importantly to the limited existing discussion on reader response in translation studies, testing with data-driven methods whether translation alterations produce different readings of the translated text, compared to the original.

\section{Heart of Darkness, racism, and reader response analysis}

For the last forty years, Conrad scholars have been discussing the potential racist and dehumanising implications of Heart of Darkness. The debate originates from a 1975 lecture (and its 1988 published version) by Chinua Achebe, in which he accuses Conrad of being a 
'thoroughgoing racist' (Achebe, 1990: 11) and Heart of Darkness of being a text 'which celebrates [the] dehumanization [of the African natives], which depersonalizes a portion of the human race' (Achebe, 1990: 12). Achebe (1990) pays particular attention to the way the African natives are represented in the text, as the passages in which they appear are, according to the critic, the 'most revealing' (Achebe, 1990: 5) of Conrad's racist attitude. He argues that the representation of the Africans only focuses on their physical appearance, on their 'blackness', without any mention of their thoughts or feelings. Africans are also deprived of human expression (Achebe, 1990: 8), lacking the ability to communicate even in their own language: "[i]n place of speech they [make] "a violent babble of uncouth sounds." (Achebe, 1990: 8). As such, they do not play an active role in the fictional world, but are reduced to props of the setting. Ultimately, the natives are dehumanised: they are eliminated as human factor and 'devoid of all recognisable humanity' (Achebe, 1990: 12). Many literary critics have responded to Achebe's (1990) claims (see for example Zins, 1982; Watts, 1983, 1990; Hawkins, 2006; Miller, 2006), and the resulting discussion is still very lively today. Surveying the various arguments in favour of and against Achebe's (1990) claims is beyond the scope of the current paper, but it is important to highlight here that the debate has shaped and keeps shaping the way Conrad and Heart of Darkness are read and interpreted (Allington, 2006).

This debate has also potential implications for the translation of Heart of Darkness. Translation is a phenomenon strictly tied to the relations between and within cultural systems (Even-Zohar, 1990). Translation is influenced by, and can influence, the sociocultural environment in which it takes place, inescapably interacting with or simply reflecting the target context of production (Lefevere, 2014). As Allington (2006: 133) explains, studying Heart of Darkness after Achebe's reading means 'to take a stand on a matter of controversy that, in the Sixties, simply did not exist - namely, whether or not it is a racist book'; translators, as informed readers whose interpretative choices can shape the TT, cannot avoid taking a stance. Whether the translator shares, disagrees, or even simply ignores Achebe's (1990) reading, intentionally or not, their decisions can nevertheless have repercussions on the TT and its reception. With their linguistic choices, translators can overstress or diminish either of the positions in relation to Achebe's (1990) critique, emphasising one reading over the other. At the lexical level, for example, the choice of which word to use or to avoid in the translation of ST items related to the representation of the Africans can influence the perception of the racist implications of the text. This is shown by Kujawska-Lis (2008), who compares two Polish translations of Heart of Darkness, one written before Achebe's (1990) lecture and the other after it. She observes that the lexical choices of the two translators to render terms like nigger, 
negro, savage, brute, etc., differ in the extent to which they emphasise or tone down the racist implications of the original: the early translator replaces potentially racist terms with neutral ones, while the later translator uses even more derogatory items than the original. Depending on which TT the target reader reads, Marlow - the main narrator of Heart of Darkness - may appear either 'as less verbally aggressive and mentally superior to the Africans' or as more 'biased both linguistically and intellectually', compared to Marlow in the ST. Author1 (2017) arrives at a similar conclusion, using a corpus stylistic approach to compare four Italian translations of Heart of Darkness. He finds that the three translations produced in the same period (1989-1990, the fourth being published in the 1920s) but published by different publishing houses differ in terms of the choices made to translate nigger $(s)$ and negro. Whereas one translation erases all occurrences of both terms, replacing them with more neutral words (e.g. nero, the Italian equivalent of 'black'), the other two not only maintain all the uses of nigger $(s)$ and negro, but also introduce additional occurrences not present in the original. These differences seem to indicate that the translators have responded, in one way or another, to the debate about racism in Heart of Darkness, as far as the depiction of the natives in the text is concerned. Both Kujawska-Lis (2008) and Author1 (2017) suggest that the textual alterations they identified have the potential to alter the interpretation of this aspect of Heart of Darkness. The reader can respond differently to the representation of the Africans in the text depending on which translation they read, affecting their perception of the text (and the author) as racist or otherwise. However, the potential of these alterations to manipulate the reader's response to the text, compared to the original, remains untested.

The current study builds on the findings of Author1 (2017). It uses responses elicited through a questionnaire to test whether differences arise in the way English and Italian readers react to potential dehumanising, discriminating, and racist implications in Heart of Darkness and in two Italian translations. As such, this study sits within the remit of reader response analysis, whose application in the field of stylistics has gained popularity in the last decade. As Whiteley and Canning (2017) explain, this approach is not new, as it draws on existing and well-established methodologies and paradigms (see Whiteley and Canning, 2017 or Harding, 2014 for an overview); however, '[t]he impulse to collect extra-textual data about literary reading in order to inform, develop and reflect upon stylistic analysis is becoming increasingly widespread' (Whiteley and Canning, 2017: 72). The collection of data through interviews, surveys, focus groups, measurements of reading and reaction times, etc. provides the stylistician with an observational basis with which to test "whether assumptions and frameworks of stylistic analysis are supported by evidence from real readers' (Peplow and 
Carter, 2014: 440). A wide range of empirical approaches and methodologies have been used to enrich and expand stylistic investigations, supporting the exploration of difficulty in poetry (Castiglione, 2017), shifts in narrative point of view (Sotirova, 2006; Cui, 2017), body language multi-word clusters in Dickens's novels (Mahlberg et al., 2014), and foregrounding (Zyngier et al., 2007), to name just a few. Yet, as mentioned in the previous section, the application of these methods to the study of reader response in translation is not as widespread.

Although the role of the reader has always been taken into account in translation studies, this role has often been held by a theorised reader, who represents an aspect of the target culture to which the translation is addressed, or as the translator-as-reader (Chan, 2016: 123), whose reading can shape the TT. Despite the recognition of the importance of the actual reader in translation research (Assis Rosa, 2006: 103), studies that concentrate on real readers and their responses are very few. For example, Li (2012) does consider real readers in his discussion of the relationship between ideology and translation, but mainly in terms of interpretative reading communities (cf. Fish, 1980), tracing the reception history of some ideologically-loaded translated texts in China (e.g. E.L. Voynich's The Gadfly and Nikolai Ostrovskii's Kak zakalialas' stal'). Studies like Li's (2012) focus more on reception patterns in large sociocultural polysystems, and not on the actual responses of individual readers. D'Egidio (2015) uses instead actual internet reviews to explore reader responses to the English translation of Camilleri's La Forma dell'Acqua and to the Italian translation of Stephen King's Joyland. Her corpus analysis offers useful insights on how readers engage with the notions of translation/translator, author, language, and style in their reviews, providing an empirical basis to delineate the reception of these TTs, but not in relation to their original. Similarly, Kruger's (2012) eye-tracking analysis of reader responses to domesticating and foreignising strategies in Afrikaans translated children's books, does not take into account the STs, but only compares responses to the TTs. One of the few studies that compares readers' responses to ST and TT is Chesnokova et al. (2017). They examine readers' reactions to the original and to the Brazilian, Russian, and Ukrainian translations of Poe's poem "The Lake" using a five-point semantic differential scale, where participants were asked to indicate their thoughts on the poem. The data show significant differences between the groups of readers, confirming that responses to the original differ from that of the translations, and between translations. However, Chesnokova et al. (2017) have no native speakers of English among their participants, so the reaction to the English text is based on the reading of speakers of English as a second language. Although this does not affect their analysis (as they are interested in cross-cultural responses 
to poetry from a comparative literature point of view), it leaves open important questions about perception of the original text by native speakers.

The current study not only compares reactions to different TTs that differ in terms of translation strategies used by the translators, but it also directly contrasts responses to the original with responses to each translation. In this way, it tests two hypotheses: (i) that responses to the ST can differ from responses to the TT as a consequence of the alterations that the text inevitably goes through during translation; and (ii) that responses to different TTs of the same ST can vary as a consequence of the diverging translation strategies adopted by and/or alterations introduced by the translators. The following section will detail the specific hypotheses that this study aims to test and the methods and procedure used. Section 4 will present the results of the study, which will be discussed in Section 5. Finally, Section 6 will provide some concluding remarks.

\section{Methods}

This article compares responses to the representation of the African natives in Heart of Darkness and two of its Italian translations. The aim is testing whether differences arise between the texts in the extent to which English and Italian readers perceive the descriptions of the Africans as being discriminating, dehumanising, and racist. The two TTs used in this study were produced in the same year, 1990. The first is the Mondadori edition, translated by Rossella Bernascone; the second is the Garzanti edition, translated by Luisa Saraval. These texts differ diametrically in the way they render the most openly racist terms in the original, nigger(s) and negro. As Author1 (2017) shows, Saraval "sanitises" the text, removing completely all the occurrences of both terms, replacing them with nero ('black'). On the other hand, Bernascone not only retains all the uses of nigger(s) and negro in Italian, but also introduces additional occurrences where the original uses black and blacks. In total, the ST uses nigger(s) and negro 13 times, Bernascone's translation uses the Italian equivalent (negro, 'nigger') 19 times, and Saraval's translation does not use these terms at all. Another relevant linguistic feature related to the representation of the natives is a set of lexico-semantic patterns that Author1 (2017) identifies in the original and links to dehumanisation. Author1 (2017) finds that the words that the ST uses to refer to the natives (including nigger and negro) share the same collocations and semantic preferences/prosody. The four semantic preferences ('Physicality', 'Collectives', 'Incomprehensibility', and 'General negative') match exactly 
what Achebe (1990) says about the way the Africans are described in Heart of Darkness, representing the linguistic instantiations of the dehumanising tendencies referred to by the critic (for a detailed description and analysis of the patterns, in the original and in the translations, see Author1, 2017). The semantic preferences/prosody are present in the translations too; it seems that the translators only altered the most obvious reflections of the racist discourse (the words used to refer to the Africans), but maintained unaltered the linguistic patterns that create dehumanisation in the text (Author1, 2017: 172).

Based on these divergences between the three texts, it was hypothesised that there would be a difference between the ST and the TTs in terms of perceived dehumanisation, discrimination, and racism. Bernascone's translation would be perceived as more racist, dehumanising, and discriminating than the original, because it uses racial slurs more frequently than the ST; Saraval's translation would be perceived as less racist, dehumanising, and discriminating than the original, because it uses no racial slurs. We also tested whether there is a difference in the perception of dehumanisation, discrimination, and racism between the two translations, as a result of the opposing strategies used by the translators. Overall, the following hypotheses were tested:

- There is a difference in the perception of dehumanisation, discrimination, and racism between the ST and the TTs:

1. Bernascone's translation is perceived as (1.a) more dehumanising, (1.b) more discriminating, and (1.c) more racist than the ST;

2. Saraval's translation is perceived as (2.a) less dehumanising, (2.b) less discriminating, and (2.c) less racist than the ST;

- There is a difference in the perception of dehumanisation, discrimination, and racism between the translations:

3. Saraval's translation is perceived as (3.a) less dehumanising, (3.b) less discriminating, and (3.c) less racist than Bernascone's translation.

To collect data on readers' responses we used an online questionnaire in three versions, one for each text. The English version was addressed to native speakers of English to gather reactions to the ST. The two Italian versions were addressed to native speakers of Italian to collect responses on the TTs. ${ }^{1}$ The Italian questionnaires were answered by different pools of participants; that is, Italian participants were either presented with Bernascone's translation or 
Saraval's. The questionnaires asked participants to read 17 extracts from the ST or one of the TTs and answer three sets of questions about these passages. The extracts were the same in all versions, but obviously differed in terms of language and text they came from. To put together the 17 extracts about the natives, we first selected all the passages in which nigger, niggers, and negro occur in the original, and their Italian versions. Then, we added to these the ones in which Bernascone introduced additional occurrences of the Italian equivalent negro ('nigger'), and their version in Saraval's translation and in the English original. The passages (usually one or two paragraphs long, between 336 and 37 words in the ST) were presented in the order they appear in the text and occasionally short notes were added between extracts to help the reader understand how one passage linked to the next (for example, 'Marlow reaches another station where he waits for months for his steamer to be repaired'). ${ }^{2}$

Three sets of questions measured readers' perception of dehumanisation, discrimination, and racism in the passages. The first set comprised of six questions to which participants were asked to answer indicating their agreement on a 7-point Likert scale (see Appendix). The items were adapted from Morena et al.'s (2016) study, which is itself based on Gray et al.'s $(2007,2011)$ dimensions of mind perception. This model evaluates 'humanness and its opposite, dehumanization' (Morena et al., 2016: 1) - defined as 'denying other people mental capacities' (Morena et al., 2016: 2) - and 'investigate[s] whether people negate distinct abilities (agency and experience) of the mind' (Morena et al., 2016: 2). The first three questions measure perception of agency (capacity of self-control, capacity to act morally, capacity to plan), while the last three questions measure perception of experience (capacity to experience emotion, capacity to experience refined or uniquely human feelings, capacity to experience consciousness). The second set equally comprised of six 6-point Likert scale questions (see Appendix) aimed at measuring perception of discrimination. The items were extracted and adapted from the Privilege and Oppression Inventory (Hays et al., 2007), a model 'designed to measure an individual's level of awareness of social issues (i.e., privilege and oppression as it relates to four primary cultural dimensions)' (Hays et al., 2007: 68). Of the four dimensions (racial, gender, sexual orientation, religious identities), we used the one related to racial issues, selecting and adapting six items from the original 13-item inventory. Finally, to measure readers' perception of racism, we used a 6-point Likert scale question asking participants to indicate to what extent they agreed or disagreed with the statement 'The representation of the African natives in these passages is racist'. Participants were also given the option to add any comment on the statement above. We could not find an existing racism measure or inventory that would work in this study, as the vast majority of established scales (cf. Kressin et al., 2008; 
Gamst et al., 2011; Atkins, 2014) measure racism and racial prejudice in the participants themselves, or their ability to be aware of it, as opposed to their perception of racism in external material (such as our extracts). The questionnaire ended with questions on the age, gender, and native language of the participants, as well as on whether they had read and/or studied Heart of Darkness before. Although we recognise that exploring the effect that these variables can have on the perception of racism, dehumnisation, and discrimination is an endeavour worth pursuing, we could not do it here, as we did not have enough data of different types of participant groups to investigate whether these variables might have influenced our findings. Dividing the participants of the three questionnaires into smaller sub-groups (e.g. male readers of the Bernascone version) would have fragmented further our pool of data. We therefore focused on the three largest data pools (readers of the Bernascone version, readers of the Saraval version, and readers of the original), in line with our research aims.

We collected 65 responses, 23 for the English version, 21 for the Bernascone version, and 21 for the Saraval version. English participants were between 18- and 61-years old, mostly women (19); 15 of them had already read Heart of Darkness and 9 had studied it too. Italian participants working with the Bernascone version were between 26 and 35 (11 female and 10 male participants). Most of them had never read (15) or studied (16) Heart of Darkness before. Italian participants completing the Saraval version were between 29 and 38 (13 male and 8 female participants). In this case too, most of them had never read (16) or studied (19) Heart of Darkness before.

\section{Results}

Table 1 shows the ratings for the questions relating to dehumanisation, discrimination and racism, which will be examined in turn below. When looking at the ratings across the different question types, it is important to note that the scale for the dehumanisation questions is different to that of discrimination and racism. This was done to ensure that the results are comparable to the literature that has developed, evaluated, and implemented the instruments to assess dehumanisation and discrimination. In order to analyse the results statistically, when comparing ratings across all three versions the Kruskal-Wallis $\mathrm{H}$ test was used, while when comparing two versions the Mann-Whitney U test was employed. 
Table 1. Mean ratings for the dehumanisation, discrimination and racism questions. For dehumanisation ratings mean values relate to agency, experience and across both, with 0 indicating not capable and 6 indicating totally capable. For the discrimination and racism ratings, 1 indicates strongly disagree and 6 indicates strongly agree

\begin{tabular}{lccc}
\hline & English & Bernascone's translation & Saraval's translation \\
\hline Dehumanisation & & & \\
$\quad$ Agency questions & 3.43 & 3.25 & 3.58 \\
Experience questions & 4.33 & 4.68 & 4.79 \\
$\quad$ Overall & 3.88 & 3.69 & 4.02 \\
Discrimination & 5.04 & 3.96 & 4.34 \\
Racism & & & \\
\hline
\end{tabular}

The six questions related to dehumanisation asked participants to evaluate, on a scale from 0 (not at all) to 6 (totally), to what extent they thought the natives in the extracts would be capable of doing a number of things based on the way they were described in the passages, not according to their own personal beliefs: (i) capable of restraining their wishes, emotions, and impulses; (ii) capable of anticipating the positive or negative consequences of their behaviour and of being responsible for their acts; (iii) capable of making plans to reach their goals; (iv) capable of experiencing emotions like fear, pain, or joy; (v) capable of experiencing feelings like shame, guilt, or hope; and (vi) capable of being conscious of their environment and of the things that happen. The first three questions tap into the participants' perception of the natives' agency in the extracts and the last three their perception of the natives' capacity to experience emotion, uniquely human feelings, and consciousness. Lower values are indicative of increased dehumanisation.

Looking at the overall perception of dehumanisation, the Kruskal-Wallis $\mathrm{H}$ test reveals no difference between the three versions $\left(\chi^{2}(2)=1.38, p>.05\right)$. When comparing the different versions to each other, the Mann-Whitney $U$ test shows no difference between the two Italian translations $(Z=-0.33, p>.05)$, and the English version and Bernascone's translation $(Z=-$ $1.61, p>.05)$. However, there is a significant difference between the English version and Saraval's translation $(Z=-2.07, p=.04)$, with dehumanisation being perceived as greater in the ST. Looking at perception of agency, there is no significant difference across the three texts $\left(\chi^{2}(2)=1.42, p>.05\right)$, nor are any of the texts different from each other in terms of perceived agency $(p$ 's $>.05)$. A similar pattern emerges regarding the capacity to experience emotion, feelings, and consciousness, with no difference across the three versions $\left(\chi^{2}(2)=2.16, p>.05\right)$, nor amongst the texts $(p$ 's $>.05)$. Notably, a comparison of agency and experience ratings 
reveals a significant difference $(Z=-6.13, p>.001)$ across all text types, indicating that readers' perception of the natives' agency is significantly less than their ability to experience emotion, feelings, and consciousness.

Turning to discrimination, six questions asked participants to judge the extracts on a scale from 1 (strongly disagree) to 6 (strongly agree): (i) the whites generally have more resources and opportunities than the African natives; (ii) the whites have the power to exclude the African natives; (iii) there are benefits to being white in the social order/context described by these passages; (iv) white cultural characteristics are more valued than those of the African natives; (v) the narrator favours the whites; and (vi) these passages negatively stereotype the African natives. Similarly, the single question on racism asked the participants to 'evaluate whether the representation of the African natives in these passages is racist', with 1 indicating strongly agree and 6 strongly disagree. For both, lower ratings are indicative of lower perception of discrimination and racism. Comparing across the three versions of the text, there is a significant difference in perceived discrimination $\left(\chi^{2}(2)=16.96, p=.001\right)$ and racism $\left(\chi^{2}(2)=6.10, p=.05\right)$. When comparing the different versions, we see that the perception of discrimination is greater in the original English text than in Bernascone's translation $(Z=-$ $3.98, p=.001)$ and Saraval's translation $(Z=-2.82, p=.01)$. However, there is no difference between the two translations $(Z=-1.31, p>.05)$. The pattern is identical for perceived racism, with racism being perceived as greater in the English version than in Bernascone's translation $(Z=-2.11, p=.04)$ and Saraval's translation $(Z=-2.16, p=.03)$, but not between the two Italian translations $(Z=-0.05, p>.05)$. These findings indicate that there is an overall effect of perceived discrimination and racism according to text type. This difference is underpinned by a greater perception of discrimination and racism in the English text compared to both the translation by Bernascone and the one by Saraval.

\section{Discussion}

Based on the results described above, we can now confirm or reject the hypotheses formulated in Section 3, as shown in Table 2 below.

Table 2. Results of the comparisons

\begin{tabular}{lll}
\hline \multicolumn{2}{l}{ Hypothesis } & Results \\
\hline $1 . \mathrm{a} \quad$ Bernascone more dehumanising than ST & rejected \\
\hline
\end{tabular}




\begin{tabular}{lll}
\hline 1.b & Bernascone more discriminating than ST & rejected \\
1.c & Bernascone more racist than ST & rejected \\
2.a & Saraval less dehumanising than ST & confirmed \\
2.b & Saraval less discriminating than ST & confirmed \\
2.c & Saraval less racist than ST & confirmed \\
3.a & Saraval less dehumanising than Bernascone & rejected \\
3.b & Saraval less discriminating than Bernascone & rejected \\
3.c & Saraval less racist than Bernascone & rejected \\
\hline
\end{tabular}

First of all, these findings show that differences arise between the texts in the extent to which English and Italian readers perceive the descriptions of the Africans as discriminating, dehumanising, and racist. Saraval's translation is generally perceived as less dehumanising, discriminating, and racist than the original. It can be assumed that the alterations introduced by the translator (i.e. the replacement of nigger(s) and negro with the Italian word for black) affected the readers' response to the text, toning down the potential racist implications of the original. However, the opposite does not happen with Bernascone's translation. We expected Bernascone's version to be perceived as more dehumanising, discriminating, and racist than the original, as a consequence of the extra occurrences of nigger $(s)$ added in this TT, but this is not the case. These results indicate that translation does manipulate reader response, but perhaps not all alterations have the same potential to impact the interpretation of the text. Our findings suggest that removing all occurrences of nigger $(s)$ and negro is more effective in affecting the response of the Italian readers than adding extra occurrences of these terms. The presence of racial slurs may be already enough to trigger racist implications, and the addition of a few more occurrences may not have any extra consequence; on the contrary, deleting completely all uses of the slurs can have a more marked effect on the perception of racism. Of course, further research is needed to substantiate these suggestions.

A second major finding of our analysis is that there is no significant difference in the readers' response between the Italian versions. The two translations do not trigger a different reaction to the text, despite the contrasting strategies used by the translators to translate nigger $(s)$ and negro, hence the perception of discrimination, dehumanisations, and racism can be considered similar in the two TTs. This may be due to the "markedness" of the lexical choices made by the translators; that is, removing or adding occurrences of nigger $(s)$ may not be a marked enough linguistic alteration to differentiate the response to two Italian versions of the same text. More relevantly, this lack of difference needs to be related to the fact that the ST is perceived as having a greater level of discrimination and racism than either the Italian 
translation. This could be the result of the diverse socio-historical load that nigger carries in the Anglo-American context, compared to the Italian equivalent (negro) in Italy. Despite both being very derogatory and racist today, the Italian word negro does not have the same history of the English nigger, given the different relationships that the source and target contexts have had with slavery, segregation, colonialism, migration, etc. In English, nigger is considered 'the most socially consequential racial insult' (Kennedy, 2002: 32), the use of which has been seen as highly racially offensive since 1800 (Hughes, 2006: 327). In contrast, the use of negro in Italy has been considered equivalent to nero ('black') until the 1970s and only at the beginning of the 1990s, with the debates on political correctness, the perception of the word has started to change (Faloppa, 2004, 2011). What is more, Faloppa (2011: 10) explains that the perception of negro as a racial slur in Italy is also the direct result of the interdiction of nigger in AngloAmerican contexts. Overall, this suggests that negro and nigger are not equivalent in terms of their racist load, which is intricately connected to their respective context of origin. Context cannot be transferred during translation and therefore the translated word loses its original contextual meanings and gains new ones in the target context. Even though Bernascone's version has more occurrences of the slur than the ST, the use of negro in Bernascone's translation may not be perceived as racist as that of nigger in the English original, whereas the presence or absence of the slur in Italian may not result in a diverse response to the two TTs. On the other hand, other aspects and features of the text, for example dehumanisation and an intrinsic derogatory representation of the natives, could be sufficient for Saraval's translation to be perceived as racist as Bernascone's, despite the absence of the openly racist word negro.

Before moving to the conclusion, it is also worth discussing the fact that, across all text types, perception of natives' agency is significantly less than their ability to experience. The consistency of this result across ST and TTs suggests that this is a feature of the text itself, as opposed to being specifically of the original or the translations. Readers are more likely to recognise in the Africans the 'capacity to be subjected to sensations (e.g., emotions, consciousness, or personality)' than the 'mental capacities that enable decision-making and organizing behaviours (e.g., idea, judgment, self-control, or communication)' (Morena et al., 2016: 2). It can be argued that the text dehumanises the natives insofar as it denies them the mental capacities to have active agency. Morena et al. (2016: 5) explain that low levels of agency could be associated with animalistic dehumanisation (considering humans as animals), while low levels of experience could be linked to mechanistic dehumanisation (considering humans as objects or robots); only high levels of both would indicate perceiving someone as a complete human being. In the case of Heart of Darkness and its translations, the greater 
perception of experience in the natives compared to their low level of agency seems to point to the animalistic metaphor of dehumanisation. The fact that all text types, despite their differences, consistently trigger the same type of dehumanisation suggests that dehumanisation is not linked to the use or avoidance of racial slurs, but is rather conveyed by other independent linguistic features (for example, the lexico-semantic patterns briefly mentioned in Section 3 and discussed in Author1 (2017) - which have been reproduced by both translators).

\section{Conclusion}

Assessing the effects of translation alterations on readers' response is a complex endeavour. If, on the one hand, we demonstrated that removing racial slurs from an Italian translation of Heart of Darkness is connected to lower perception of dehumanisation, discrimination, and racism compared to the original, on the other hand, we also found that the opposite strategy (i.e. adding racist terms) does not produce the opposite result. We believe that this is a reflection of the multifaceted nature of the translation phenomenon: the words the translator uses are only part of the picture and the effect they can have on the reader is not one-dimensional, but can vary depending on intricate interactions with the context of reception and other linguistic features. Although our results indicate that translation can manipulate reactions to the text, further research is needed to explore the multidimensional relationships between linguistic alterations and reader response in translation.

\section{Declaration of Conflicting Interests}

The authors declared no potential conflicts of interest with respect to the research, authorship, and/or publication of this article.

\section{Funding}

The authors received no financial support for the research, authorship, and/or publication of this article.

\section{Notes}

1. In translating the questionnaire from English into Italian, we made sure that no linguistic difference could have a significant effect on the participants' responses. We can therefore consider the two versions equivalent, as far as the retrieval of data is concerned. 
2. These notes are typographically presented as extra-textual material, not part of the original text.

\section{References}

Achebe C (1990) An image of Africa: Racism in Conrad's Heart of Darkness. In: Hopes and Impediments: Selected Essays. New York, NY: Anchor Books, pp.1-20.

Allington D (2006). First steps towards a rhetorical psychology of literary interpretation. Journal of Literary Semantics 35(2): 123-44.

Assis Rosa A (2006) Defining target text reader: Translation studies and literary theory. In: Duarte J F, Assis, R A and Seruya T (eds) Translation Studies at the Interface of Disciplines. Amsterdam: John Benjamins, pp.99-109.

Atkins R (2014) Instruments measuring perceived racism/racial discrimination: review and critique of factor analytic techniques. International Journal of Health Services 44(4): 711-734.

Author1 and Colleague (2017).

Author1 (2017).

Boase-Beier J (2014) Translation and the representation of thought: The case of Herta Müller. Language and Literature 23(3): 213-226.

Bosseaux C (2004) Translating point of view: A corpus-based study. Language Matters: Studies in the Language of Africa 35(1): 259-74.

Bosseaux C (2006) Who's afraid of Virginia's you: A corpus-based study of the French translations of The Waves. Meta: Journal des Traducteurs/Meta: Translators'Journal 51(3): 599-610.

Castiglione D (2017) Difficult poetry processing: Reading times and the narrativity hypothesis. Language and Literature 26(2): 99-121.

Čermáková A (2015) Repetition in John Irving's novel A Widow for One Year: A corpus stylistics approach to literary translation. International Journal of Corpus Linguistics 20(3): 355-77.

Čermáková A and Fárová L (2010) Keywords in Harry Potter and their Czech and Finnish translation equivalents. In: Čermák F, Klégr A and Corness P (eds) InterCorp: Exploring a Multilingual Corpus. Studie z korpusové lingvistiky, svazek 13. Prague: Nakladatelství Lidové noviny/Ústav českého národní ho korpusu, pp.177-88.

Chan L T-H (2016) Reader response and reception theory. In: Baer B J and Angelelli C (eds) Researching Translation and Interpreting. London: Routledge.

Chesnokova A, Zyngier S, Viana V, Jandre J, Rumbesht A and Ribeiro F (2017) Cross-cultural reader response to original and translated poetry: An empirical study in four languages. Comparative Literature Studies 54 (4): 824-849.

Cui Y (2017) Reader responses to shifts in point of view: An empirical study. Language and Literature 26(2): 122-136.

D’Egidio A (2015) How readers perceive translated literary works: An analysis of reader reception.

Lingue e Linguaggi 14: 60-82. 
Dukāte A (2009) Translation, Manipulation and Interpreting. Frankfurt: Peter Lang.

Even-Zohar I (1990). Polysystem studies. Poetics Today 11(1): 1-268.

Faloppa F (2004) Parole Contro: La Rappresentazione del Diverso in Italiano e nei Dialetti. Milano: Garzanti.

Faloppa F (2011) Risposta al quesito di Paola Costantini sulle forme nero e di colore. Crusca per Voi 43: 10 .

Farahzad F (2003) Manipulation in translation. Perspectives: Studies in Translatology 11 (4): 269-281.

Fish S E (1980) Is There a Text in This Class? The Authority of Interpretative Communities. Cambridge, MA: Harvard University Press.

Gamst G C, Liang C T H and Der-Karabetia A (2011) Racism- and prejudice-related measures. In: Handbook of Multicultural Measures. Newbury Park, CA: Sage, 251-333.

Gray K, Knobe J, Sheskin M, Bloom P and Barrett L F (2011) More than a body: Mind perception and the nature of objectification. Journal of Personality \& Social Psychology 101(6): 1207-1220.

Gray H M, Gray K and Wegner D M (2007) Dimensions of mind perception. Science 315 (5812): 619. Harding J R (2014) Reader response criticism and stylistics. In: Burke M (ed) The Routledge Handbook of Stylistics. Abingdon: Routledge, pp.68-84.

Hawkins H (2006). Heart of Darkness and racism. In: Armstrong P B (ed) Heart of Darkness. New York, NY: Norton, pp.365-375.

Hays D G, Chang C Y and Decker S L (2007) Initial development and psychometric data for the Privilege and Oppression Inventory. Measurement and Evaluation in Counselling and Development 40: 66-79.

Hermans T (ed) (2014) The Manipulation of Literature: Studies in Literary Translations. London: Routledge. (Original work published in 1985)

Johnson J H (2016) A comparable comparison? A corpus stylistic analysis of the Italian translation of Julian Barnes' Il Senso di una Fine and the original text The Sense of an Ending. Language and Literature 25(1): 38-53.

Kennedy R (2002). Nigger: The Strange Career of a Troublesome Word. New York, NY: Pantheon Books.

Kressin N R, Raymond K L and Manze M (2008) Perceptions of race/ethnicity-based discrimination: A review of measures and evaluation of their usefulness for the health care setting. Journal of Health Care for the Poor and Underserved 19(3): 697-730.

Kruger H (2012) Reader responses to domesticating and foreignising translation strategies: An eyetracking experiment. In: Postcolonial Polysystems: The Production and Reception of Translated Children's Literature in South Africa. Amsterdam: John Benjamins, pp. 217-267.

Kujawska-Lis E (2008) Turning Heart of Darkness into a racist text: A comparison of two Polish translations. Conradiana 40 (2): 165-78.

Lefevere A (1992) Translation, Rewriting, and the Manipulation of Literary Fame. London: Routledge. 
Li P (2012) Ideology-oriented translations in China: A reader-response study. Perspectives: Studies in Translatology 20 (2): 127-137.

Mahlberg M, Conklin K and Bisson M-J (2014) Reading Dickens's characters: Employing psycholinguistic methods to investigate the cognitive reality of patterns in texts. Language and Literature 23 (4): 369-88.

Miller J H (2006) Should we read Heart of Darkness? In: Armstrong P B (ed) Heart of Darkness. New York, NY: Norton, pp.463-474.

Morena M D, Quiles M N, Correa A D, Delgado N and Leyens J-P (2018) Perception of mind and dehumanisation: Human, animal, or machine? International Journal of Psychology 53(4): 253260.

Morini M (2007) Say what you mean, mean what you say: A pragmatic analysis of the Italian translations of Emma. Language and Literature 16(1): 5-19.

Munday J (2008). Style and Ideology in Translation: Latin America Writing in English. London: Routledge.

Peplow D and Carter R (2014) Stylistics and real readers. In: Burke M (ed) The Routledge Handbook of Stylistics. Abingdon: Routledge, pp.440-454.

Sotirova V (2006) Reader responses to narrative point of view. Poetics 34(2): 108-133.

Venuti L (2013) Translation Changes Everything: Theory and Practice. London: Routledge.

Watts C E (1983) 'A bloody racist': About Achebe's view of Conrad. The Yearbook of English Studies 23: 196-209.

Watts C E (1990) Heart of Darkness and Other Tales. Oxford: Oxford University Press.

Winters M (2009) Modal particles explained: How modal particles creep into translations and reveal translators' styles. Target 21(1): 74-97.

Winters M (2010) From modal particles to point of view: A theoretical framework for the analysis of translator attitude. Translation and Interpreting Studies 5(2): 163-85.

Yu J (2017) Translating 'others' as 'us' in Huckleberry Finn: Dialect, register and the heterogeneity of standard language. Language and Literature 26 (1): 54-65.

Zins H (1982) Joseph Conrad and Africa. Nairobi: Kenya Literature Bureau.

Zyngier S, van Peer W and Hakemulder J F (2007) Complexity and foregrounding: In the eye of the beholder? Poetics Today 28(4): 653-682.

\section{Appendix}

\section{English questionnaire}

1. Purely based on the way the African natives are described in these passages - NOT according to your personal beliefs - to what extent do you think the natives would be:

\begin{tabular}{|l|c|c|c|c|c|c|c|}
\hline & $\begin{array}{c}0 \\
\text { Not at all }\end{array}$ & 1 & 2 & 3 & 4 & 5 & $\begin{array}{c}6 \\
\text { Totally }\end{array}$ \\
\hline Capable of restraining their wishes, emotions, and impulses? & & & & & & \\
\hline
\end{tabular}




\begin{tabular}{|l|l|l|l|l|l|}
\hline $\begin{array}{l}\text { Capable of anticipating the positive or negative consequences } \\
\text { of their behaviour and of being responsible for their acts? }\end{array}$ & & & & & \\
\hline Capable of making plans to reach their goals? & & & & & \\
\hline Capable of experiencing emotions like fear, pain, or joy? & & & & & \\
\hline Capable of experiencing feelings like shame, guilt, or hope? & & & & & \\
\hline $\begin{array}{l}\text { Capable of being conscious of their environment and of the } \\
\text { things that happen? }\end{array}$ & & & & & \\
\hline
\end{tabular}

2. Purely based on the way the African natives are described in these passages - NOT according to your personal views or the modern context - do you think that the following are true?

\begin{tabular}{|c|c|c|c|c|c|c|}
\hline & $\begin{array}{c}1 \\
\text { Strongly } \\
\text { disagree }\end{array}$ & 2 & 3 & 4 & 5 & $\begin{array}{c}6 \\
\text { Strongly } \\
\text { agree }\end{array}$ \\
\hline $\begin{array}{l}\text { The whites generally have more resources and opportunities } \\
\text { than the African natives. }\end{array}$ & & & & & & \\
\hline The whites have the power to exclude the African natives. & & & & & & \\
\hline $\begin{array}{l}\text { There are benefits to being white in the social order/context } \\
\text { described by these passages. }\end{array}$ & & & & & & \\
\hline $\begin{array}{l}\text { White cultural characteristics are more valued than those of the } \\
\text { African natives. }\end{array}$ & & & & & & \\
\hline The narrator favours the whites. & & & & & & \\
\hline These passages negatively stereotype the African natives. & & & & & & \\
\hline
\end{tabular}

3. To what extent do you agree or disagree with the following statement?

\begin{tabular}{|l|c|c|c|c|c|c|}
\hline & $\begin{array}{c}1 \\
\text { Strongly } \\
\text { disagree }\end{array}$ & 2 & 3 & 4 & 5 & $\begin{array}{c}6 \\
\text { Strongly } \\
\text { agree }\end{array}$ \\
\hline $\begin{array}{l}\text { The representation of the African natives in these passages is } \\
\text { racist. }\end{array}$ & & & & \\
\hline
\end{tabular}

4. Any comments on the statement above or anything related you would like to add? (optional)

5. Age (number, e.g. 32)

6. Gender

7. Native language

8. Have you read Heart of Darkness before?

9. Have you studied Heart of Darkness before? 